ARTIGO

Recebido em:

$18 / 12 / 2015$

Aceito em:

$19 / 03 / 2016$

Encontros Bibli: revista eletrônica de biblioteconomia e ciência da informação, v. 21, n. 46, p.

33-44, mai./ago., 2016. ISSN 1518-2924. DOI: 10.5007/1518-2924.2016v21n46p33

\title{
A Indexação e a Arquivística: aproximações iniciais no universo teórico da organização e representação do conhecimento
}

\author{
Indexing and Archival Science: initial approximations in the \\ universe of knowledge organization and representation
}

Thiago Henrique Bragato BARROS

Professor Adjunto na Faculdade de Arquivologia (UFPA) - sean.vogel@gmail.com

\begin{abstract}
Resumo
A Arquivística tem passado por uma série de mudanças teórico-conceituais nas últimas duas décadas, essas modificações ocorreram devido em grande parte ao uso e produção de documentos em meios digitais e no modo de usar e buscar conteúdos informacionais. Neste sentido, práticas de indexação podem contribuir e facilitar o acesso às informações orgânicas. Trabalha-se com a representação arquivística como uma base para abordagem de duas funções arquivísticas: a classificação e a descrição. Compreendendo-as como parte de um processo de representação no ambiente de arquivos discute-se o percurso histórico destas funções a fim de aproximá-las da representação e finalmente, da indexação. Este esforço visa contribuir conceitualmente para a organização e representação de conhecimento em ambiente de arquivo. Chegou-se a delimitação de pontos de contato entre a indexação e a Arquivística como esse processo difere-se daquele que ocorre no âmbito de outras instituições documentais, na medida em que o contexto é a partícula básica para a organização de arquivos. Concluiu-se que a indexação pode sim auxiliar metodologicamente a Arquivística na construção dos descritores e planos de classificação.
\end{abstract}

Palavras-chave: Classificação. Descrição. Representação Arquivística. Indexação. Organização do Conhecimento.

\begin{abstract}
The Archival Science has experienced a series of theoretical and conceptual changes over the past two decades, these changes were due largely to the use and production of documents in digital media and in the way we use and seek informational content. In this sense, indexing practices can contribute and facilitate access to organic information. We works with archival science representation as an approach basis for two major archival functions: classification and description. Understanding them as part of a representation process in the record environment we discusses the historical background of these functions in order to bring them closer to representation and finally to the indexing practice. This effort aims to contribute conceptually to the organization and representation archival knowledge. We were reached demarcation points between archival science and indexing such process differs from that which occurs within other documental institutions, to the extent that the context is the basic particle for organizing records. We concluded that indexing could indeed help methodologically the archival science in the construction of descriptors and classification schemes.
\end{abstract}

Keywords: Classification. Archival Description. Archival Representation. Indexing. Knowledge Organization.

v. 21, n. 46,2016

p. $33-44$

ISSN 1518-2924
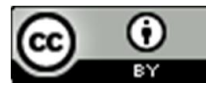

Esta obra está licenciada sob uma Licença Creative Commons. 


\section{INTRODUÇÃO}

As metodologias de tratamento documental na Arquivística passaram por uma série de mudanças nos últimos 20 anos. Essas modificações possuíram como fator determinante o uso massivo no ambiente institucional de tecnologias de informação e a produção eletrônica de documentos.

No contexto atual a produção de documentos de arquivo encontra-se em uma situação híbrida na qual documentos em papel são produzidos concomitantemente a documentos digitais e vice versa.

A indexação enquanto parte de um processo de representação do conteúdo documental ainda é pouco utilizada no contexto teórico-metodológico dos arquivos e da Arquivística e seu uso muitas vezes ocorre de forma improvisada e incongruente.

Contudo, os processos de indexação podem auxiliar no processo de análise e síntese que ocorre ao longo da descrição e representação de arquivos ou mesmo na definição de séries e identificação de conjuntos documentais no âmbito da classificação que incide inclusive, nos documentos produzidos em ambientes abertos e digitais.

Neste sentido, este artigo busca traçar um panorama teórico dos possíveis pontos de contato entre a indexação e a Arquivística, e como o processo de indexação reflete metodologicamente na representação arquivística como conceitua Yekel (2003).

Assim, trata-se de uma reflexão em primeira instância teórica na medida em que estuda a representação arquivística em relação à indexação e sua aplicação na realidade dos arquivos, e em um segundo momento utiliza-se do referencial teórico construído a partir dessa correlação no contexto da descrição e classificação de arquivos. Construindo um arcabouço teórico-conceitual, correlacionado essas áreas visando uma aproximação com a Ciência da Informação e Organização da informação de forma efetiva.

Chegou-se a resultados interessantes a respeito da construção de índices no caso da descrição de arquivos e na nomeação das séries no âmbito da classificação.

Assim, o problema de pesquisa partiu de uma necessidade de buscar sistematizar e identificar o uso da indexação no âmbito da organização do conhecimento arquivístico e como pode ser aplicada a indexação na prática arquivística.

A hipótese é de que o processo de indexação pode ser aplicado à realidade dos arquivos e auxiliar em atividades cruciais ao acesso à informação arquivística.

Deste modo, objetivou-se por meio do quadro teórico-metodológico construído a partir da representação de arquivos como ocorre e como se aplica a indexação em arquivos, visando assim sintetizar e sistematizar o seu uso, uma vez que, trata-se de uma temática pouco explorada no âmbito da Arquivística e da organização do conhecimento.

Assim, chegou-se a delimitação de pontos de contato entre a indexação e a Arquivística, e como esse processo difere-se daquele que ocorre no âmbito de outras instituições documentais.

Concluiu-se que a indexação pode sim auxiliar metodologicamente a Arquivística enquanto parte do processo de representação no âmbito dos arquivos.

\section{REPRESENTAÇÃO EM ARQUIVOS: DESCRIÇÃO E CLASSIFICAÇÃO ENQUANTO UM PROCESSO DE REPRESENTAÇÃO}

Historicamente os processos de classificação e descrição de arquivos ainda tidos como fundamentais e os primeiros a serem efetivamente conceituados na 
prática dos arquivos, não eram compreendidos enquanto um processo. Isso passa a mudar ao longo da década de 1980 e 1990 com o início da integração entre as atividades de organização de arquivos e de um processo de maior institucionalização da área. (BARROS, 2014; BARROS, MORAES, 2013)

Porém, na teoria arquivística, só recentemente ambas as atividades começaram a serem vistas como um processo único e contínuo de análise e síntese da informação contida nos arquivos, ou seja, o processo compreendido aqui como a representação orgânico-contextual.

Descreve-se ao longo desta seção o percurso histórico da classificação e descrição arquivística, visando demarcar o espaço de atuação do processo de representação em arquivos.

\subsection{Classificação: A atividade limite do âmbito dos arquivos}

Classificação na realidade dos arquivos é considerada uma atividade limítrofe na medida em que constrói uma ponte entre as atividades de gestão e as atividades de acesso e preservação documental.

A classificação, assim como a descrição foram as primeiras atividades a serem, de algum modo, conceituadas na teoria e prática arquivística desenvolvidas a partir do século XIX, como foi sinalizado anteriormente.

Os princípios básicos da proveniência e ordem original irão estabelecer-se desde o final do século XIX como fundamentais para a organização dos arquivos.

No início do século XX, a classificação dá um pequeno salto com as reconsiderações a respeito do tema publicadas por Hillary Jenkinson em 1922. Para o autor, a classificação é dividida em duas partes "a primeira estuda a administração da instituição, sua história e organização; a segunda divide os arquivos em classes e suas subdivisões" (JENKINSON, 1922, p. 81, tradução nossa).

A classificação, enquanto teoria, desenvolve-se de maneira plena a partir da década de 1960-1970 com as publicações de Theodore R. Schellenberg, Oliver W. Holmes, Ernest Posner, Petter Scott, dentre outros arquivistas e pesquisadores dos Arquivos Nacionais dos Estados Unidos e da Austrália.

Ao mesmo tempo em que a disciplina avança de maneira profunda, a partir da década de 1950, ocorre uma ruptura que irá perpetuar-se ao longo das décadas até a atualidade.

Trata-se da separação de certas atividades e conceitos determinados pela fase em que os documentos se encontram.

Uma das instituições responsáveis por esse acontecimento é o Arquivo Nacional Americano, centralizado na figura de Theodore R. Schellenberg, que difundiu e popularizou seus métodos, separando a classificação como uma atividade típica de arquivos ativos e o arranjo aos arquivos permanentes, dando início de uma ruptura sistemática na disciplina.

Observe-se que anteriormente não existia uma diferença entre essas funções, e o uso mais corrente era o termo arranjo para designar coisas que, para a arquivística americana, depois de década de 1950, são diferentes. Eastwood faz uma ponderação fundamental a respeito desse problema terminológico-conceitual:

A escolha da palavra "arranjo" como nome deste processo é infeliz. Denota colocar coisas de um modo aceitável, um uma ordem conveniente, e como arranjar livros em uma prateleira. A palavra classificação não é mais satisfatória, neste caso denota o arranjo ou a ordenação de coisas por classes e é um termo melhor reservado na arquivística para o processo de organizar documentos ativos. (EASTWOOD, 2000, p. 93, tradução nossa).

A classificação por funções é hoje, ao mesmo tempo, o trunfo e o simulacro da arquivística, no sentido de que para alguns autores é por esse olhar que se define 
a atividade como, por exemplo, para Shepherd e Yeo (2003, p. 44, tradução nossa): "Esquemas de classificação são baseados na análise das funções, processos e atividades".

A classificação é uma atividade gerencial e de planejamento não só para os arquivos, mas para as administrações que geraram os documentos. Assim, a construção do plano de classificação deve contemplar as relações entre os documentos, mas não só essas, também, as relações entre os documentos e as pessoas, assim, o sistema de classificação se tornaria uma ferramenta útil e facilitadora da descrição e avaliação dos documentos.

Assim, a classificação funciona como a base para todos os processos de organização de arquivos e evidentemente para a representação do conhecimento arquivístico.

Compreendendo a classificação arquivística como parte de um processo de representação de arquivos significa então, que o plano de classificação desenvolvido irá servir de base para a construção de índices e vocabulários controlados e efetivamente auxiliar na descrição de documentos.

Portanto, a elaboração dos indexadores está condicionada a construção do plano de classificação funcional estabelecendo-se na relação contexto-conteúdo, ou seja, a indexação em relação a classificação dependeria dos descritores construídos a partir do estudo do órgão produtor de documentos.

\subsection{Descrição Arquivística: representação e acesso}

A palavra descrição é originada do termo latino descriptio, originado do termo describere, que significa transcrever, copiar, narrar, definir, distribuir, colocar em classes, escrever sobre. Portanto, o termo descrição arquivística significa, literalmente, escrever sobre o material arquivístico e abarca as ideias de representação, identificação e organização.

Essa atividade de descrever sobre os documentos de arquivo esteve presente desde os tempos mais remotos, e seus objetivos mudaram com o passar do tempo especialmente após a revolução francesa (BARROS; TOGNOLI, 2015).

$\mathrm{Na}$ Antiguidade, por exemplo, repertórios de documentos eram construídos em tábuas de argila, e serviam para impedir a consulta direta aos documentos e manter o conteúdo dos documentos em caso de deslocamento repentino ou em caso de guerra ou fogo. Neste caso, o ato de descrever estava ligado à preservação dos registros, é claro que neste momento não está se falando em arquivos na perspectiva moderna, nem mesmo nos documentos que hoje são compreendidos como arquivísticos, mas o que é importante destacar é que existe, desde o início da civilização humana uma necessidade de sintetizar e representar documentos a fim de preserva-los e recuperá-los.

Na Idade Média, inventários eram compilados com o objetivo de fornecer provas da existência de documentos; ou armazenar o material preservado para os sucessores custodiadores. Aqui, além de preservar os documentos, a descrição tinha um objetivo jurídico, pois fornecia prova da existência dos documentos, e administrativo, uma vez que possibilitava ao custodiador dos documentos para manter o controle sobre os fundos e facilitar a recuperação da informação para fins de valor primário).

Essa interpretação, evidentemente, calcada e fundamentada na perspectiva moderna do que vem a ser a descrição o papel dos arquivos na sociedade. Porém, novamente, sinaliza a importância e relevância do tema ao longo do tempo.

Apesar de o ato de descrever documentos exista desde a Antiguidade, o termo "descrição arquivística" e sua junção à classificação, enquanto duas atividades integradas datam do século XX, fruto do movimento historiográfico e científico da época que passam a entender o documento de arquivo como testemunho para os estudos do passado relacionado fundamentalmente com os documentos medievais. 
Durante esse período, mais um objetivo é adicionado à atividade de descrever: fornecer acesso aos documentos. Com a abertura dos arquivos ao cidadão, depois da Revolução Francesa, percebe-se que mais pessoas além do criador e de alguns estudiosos acadêmicos, começam a usar o material arquivístico. Logo, faz-se necessário uma adaptação e redirecionamento da atividade de descrição, como destaca Duranti (1993, p.50)

[...] a descrição vem perdendo progressivamente seus objetivos de prestar contas dos fundos da instituição arquivística, facilitando a recuperação física de documentos e fornecendo acesso à informação. Esses objetivos são agora preenchidos pela compilação de registros de acesso, listas de localização, índices e todos os tipos de instrumentos de recuperação. O principal objetivo de escrever sobre os documentos é destacar as relações contextuais e de proveniência.

Portanto, a partir do século XX, a descrição começa a se preocupar menos com a criação de simples instrumentos de pesquisa e substitutos dos documentos, e passa a focar na relação do documento com seu contexto, trabalhando em paralelo com a classificação.

Pode-se dizer, então, que descrever é um processo que permite ao arquivista representar - no sentido mais denotativo do termo - todo o conhecimento que é mantido em seu arquivo.

Portanto, a descrição visa explicar os documentos, serve para tornar possível a compreensão do acervo/fundo arquivístico, sua origem, seu contexto e proveniência, seu método de arquivamento, sua forma e conteúdo, a relação com outros documentos, e a forma de como encontrar a informação que se procura. Objetivando, portanto, controlar, recuperar e fornecer acesso aos documentos.

Para Rodrigues (2003, p.217) a descrição é uma função-chave no que diz respeito à representação das informações arquivísticas e na possibilidade de acesso a elas.

Esta representação vai além do documento, perpassando suas funções e seus órgãos produtores. Neste sentido, o princípio de respeito aos fundos exerce, mais uma vez, um papel central no estabelecimento dos níveis que serão descritos.

Uma das preocupações maiores em relação à descrição relaciona-se com a terminologia empregada nos diferentes instrumentos de pesquisa, que podem ser agrupados em três grandes conjuntos: guias, inventários e catálogos.

A existência destes três tipos de instrumentos não significa que haja uma uniformidade terminológica em relação a eles, à própria tarefa de descrição, ou mesmo às unidades e agrupamentos a serem descritos.

Assim, existirá, ao longo da década de 1980, a necessidade de reconhecimento e delimitação dos tipos, bem como das prioridades na elaboração dos instrumentos de pesquisa.

Nesse esforço delimitador, uma das autoras mais citadas é Heredia Herrera, que, desde o início dos anos 1980, procura delimitar e diferenciar os vários tipos de instrumentos de pesquisa. Pode-se compreendê-los do seguinte modo:

1. Guia: uma "visão panorâmica e genérica dos fundos e grupos documentais de um conjunto de arquivos, relacionados a um denominador comum, um arquivo ou uma seção ou uma série, acompanha tudo que pode iluminar seu valor e seu sentido" (HEREDIA HERRERA, 1982, p.25-26). Há ainda dois tipos de guias complementares: os guias gerais e o guia especial. Os guias gerais, como o próprio nome diz, são mais genéricos e descrevem a instituição Arquivística como um todo; já o guia especial se relaciona mais com os fundos documentais do que com arquivo em si. 
2. Inventário: um instrumento de controle e de orientação para o investigador. Os elementos fundamentais que um inventário deve conter são "nome dado e formato do fundo (livro, pasta), entrada descritiva (tipológica e tradição documental, autor, destinatário, assunto se possível) e datas limites" (HEREDIA HERRERA, 1982, p.30-31).

3. Catálogo: "o objeto da descrição dever ser a peça documental, entendido como o documento solto, considerando documento principal (carta, escritura, testamento, escritura de venda) e a unidade Arquivística ao qual se relaciona" (HEREDIA HERRERA, 1982, p.78). O catálogo deve conter todos os dados fundamentais para identificação do documento: dados externos, assinaturas, autor, assunto, podendo ser cronológico e alfabético.

4. Instrumentos auxiliares de descrição: podemos destacar os índices, tesauros e indexações relacionados à linguagem documental, concebidos como instrumentos facilitadores e especializados dentro do universo dos arquivos (HEREDIA HERRERA, 1995).

Durante a década de 1980, surge uma pluralidade de interpretações e diferenças em relação aos tipos de instrumentos, mesmo que três conjuntos permaneçam como base para a elaboração. A própria nomeação dos diferentes instrumentos causa confusão, como percebidos nos seguintes agrupamentos:

1. Os guias. Dos quais se diferenciam: o guia-censo, guia de fontes, guia orgânico e guia de arquivos.

2. Os inventários. Dos quais se diferenciam o inventário analítico e o inventário sumário

3. Os catálogos. Dos quais se diferenciam o catálogo de documentos e o catálogo de expedientes (CRUZ MUNDET, 2001, p.272-296, tradução nossa).

A multiplicidade de tipos de instrumentos dificulta não só sua elaboração, mas também o acesso aos documentos, uma vez que o usurário necessita de conhecimento prévio e os tipos de instrumentos diferenciam-se de instituição para instituição.

Baseando-se nesses dois autores, pode-se dizer que, privilegiam-se os guias, os inventários e os catálogos.

Os instrumentos mais importantes, nessa perceptiva, são os gerais e não os específicos, uma vez que as relações entre os documentos no ambiente arquivístico acontecem por meio do contexto.

A grande diferença ocorre quando se pensa na falta de parâmetro nos instrumentos auxiliares, com seu uso mudando ou não de instituição para instituição.

Existirá a partir da década de 1980, um impulso por parte da comunidade Arquivística que levará a normalização da descrição. Especialmente no Canadá, Reino Unido e Estados Unidos, a promulgação de alguma norma de descrição ocorrerá ao longo da década de 1980 nos países destacados acima e ao longo da década de 1990 ocorre a formulação das normas do Conselho Internacional de Arquivos (ICA, em inglês).

Complementando e correlacionando a descrição à representação, compreende-se a função da seguinte maneira:

A descrição é a análise realizada por um arquivista sobre os fundos e os documentos de arquivo agrupados natural ou artificialmente, a fim de sintetizar e condensar a informação nos conteúdos para os interessados. [...] A descrição é a ponte de comunicação entre os documentos e os usuários. Na cabeça da ponte, está o arquivista, que realiza uma tarefa de análise que supõe identificação, leitura, 
resumo e indicação, transmitindo ao usuário para que este inicie a recuperação em sentido inverso a partir dos índices (HEREDIA HERRERA, 1995, p. 300, tradução nossa).

Com a analogia da descrição funcionando como uma ponte com usuários coloca-se a descrição como um processo fundamental para a recuperação dos documentos arquivísticos, visando ao uso. Esta atividade é, portanto, de síntese e aproxima o trabalho arquivístico dos usuários de arquivo.

A primeira reunião formal para discussão dos princípios de descrição, buscando estabelecer parâmetros que visam à normalização, aconteceu em 1992, com a publicação pelo ICA e por outros membros participantes - dentre eles, Espanha, Canadá e Brasil - do documento intitulado Statament of principles regarding archival description. Nesse documento, estabelece-se o "esqueleto" do que seria a descrição multinível proposta pelo ICA, baseado nas normas nacionais do Reino Unido e do Canadá.

Em 1994, surgiu a primeira versão da norma de descrição publicada pelo ICA: a ISAD(G). A partir desse momento, inicia-se a difusão do uso desta norma como parâmetro para a descrição, abrindo precedente para revisão das práticas em descrição em uma série de países - dentre os quais se inclui uma série de países na América Latina e Europa, levando à produção, na década seguinte, de versões nacionais da norma e de uma grande revisão dos instrumentos de pesquisa produzidos até então.

A partir da primeira versão, uma série de outras normas surge ao longo dos anos 1990 e 2000, até que, em 2007, inicia-se a formulação de uma norma nacional de descrição Arquivística na Espanha, com a criação da Comisión de Normas Españolas de Descripción Archivística (CNEDA), trata-se do projeto Norma Española de Descripcion Archivistica (NEDA).

Esta se encontra na primeira versão e busca esquematizar, para a realidade espanhola, os campos já definidos pela ISAD(G).

A primeira versão da norma é de 2005 e, nos últimos três anos, tem sido revista, comprováveis alterações em 2014-2015, com a versão final do Modelo Conceptual de Descripción Archivística y Requisitos de Datos Básicos de las Descripciones de Documentos de Archivo, Agentes y Funciones , que nada mais é do que a versão nacional das normas ISAD(G) e ISAAR(CPF) (COMISIÓN DE NORMAS ESPAÑOLAS DE DESCRIPCIÓN ARCHIVÍSTICA, 2011).

O mesmo ocorreu em outros países da América Latina, porém, as normas não são exatamente novas normas foram efetuados adaptações de forma localizada, exemplo da própria realidade brasileira com a NOBRADE (Norma Brasileira de Descrição Arquivística), mudanças profundamente pontuais e reducionistas.

As mudanças ocorridas no início do século XIX demarcaram o aparecimento dos arquivos modernos. A influência francesa perpetua-se ao longo do século XIX, com o aparecimento de estabelecimentos visando o ensino de práticas voltadas à organização de arquivos incidindo diretamente no perfil dos arquivistas, para além daquela época.

Proliferam-se, ao longo dos anos 1980 e 1990, manuais e obras voltadas para a discussão dos parâmetros metodológicos e científicos da Arquivística, endossando a acepção de que a Arquivística, por sua condição de existência, estabelece-se de forma tecnicista e voltada para questões eminentemente histórico-culturais.

Assim, a descrição arquivística apoia as questões metodológicas e técnicas, em detrimento de questões conceituais e epistemológicas, ainda que produza mais recentemente textos voltados para a discussão de teorias.

A compreensão da descrição e classificação enquanto atividades conjuntas possibilita a existência de relações interdisciplinares entre a Arquivística e a Organização do Conhecimento, possibilitando a primeira abordagens teórico metodológicas constituindo um novo momento para a organização de arquivos e 
neste universo apropriar-se de metodologias de tratamento, como aquelas presentes nos processos de indexação.

Assim, as técnicas de organização e acesso a documentos de arquivo ao longo do tempo foram se refinando e se modificando, neste sentido, a aproximação entre a indexação e a representação em arquivos é mais um passo ao melhor acesso à informação orgânica produzida pelas instituições publicas e privadas.

Na seção a seguir discute-se princípios da indexação em arquivos e as relações entre a representação arquivística e a indexação.

\section{INDEXAÇÃO E REPRESENTAÇÃO DE ARQUIVOS}

A indexação é um processo que visa à recuperação de conteúdos contida em um documento, por meio de termos (conceitos, termos, palavras-chave).

Buscando a construção de mapas conceituais, vocabulários controlados, índices, tesauros, uma gama ampla de ferramentas que visam representar os documentos, na parte e no todo.

Os conceitos são extraídos do texto original ou são selecionados a partir de uma linguagem documentária. Esse processo se dá por meio de representações do conteúdo encontrado nesses documentos e de uma linguagem documental, cuja produção resulta em resumos, índices de assuntos.

É evidente na bibliografia em indexação que o processo ainda permanece bastante subjetivo, ainda que o tema seja estudado com profundidade por uma série de pesquisadores como, Fujita (2003), Redígolo e Fujita (2009), Chamuier (1988), Guimarães (2003), dentre outros, ainda assim, constitui-se de um processo intelectual humano, de leitura, interpretação e análise, definindo o que será indexado, ou seja, representando uma tomada de decisão, envolvendo inclusive, o contexto para o qual o documento está sendo indexado.

Assim como a descrição e classificação em arquivos, o processo de documentar e representar conteúdos é latente e presente em nas civilizações humanas que desenvolveram a escrita, porém, é no século XIX que se inicia o percurso de desenvolvimento da indexação enquanto uma função "foram encontradas formas de representação condensada que davam acesso aos conteúdos dos documentos, [em períodos anteriores] até o grande desenvolvimento da indexação que se dá ao final do século XIX com o aumento de publicações periódicas e da literatura técnico científica de modo geral" (FUJITA, RUBI, BOCCATO, 2009 p. 22, comentário nosso).

A indexação será impulsionada no início do século XX com os trabalhos de Paul Otlet e Henri de La Fontaine. Anos mais tarde os trabalhos de Sussane Briet também foram importantes para a documentação, a Ciência da Informação e evidentemente a indexação (DAY, 2001).

Passos foram dados a partir da documentação e da Ciência da Informação, criando-se em 1985 pela International Standardization for Organization (ISO), sob número 5.963, com o título Documentation - methods for examining documents, determining their subjects, and selecting indexing terms a primeira norma de descrição (FUJITA, RUBI, BOCCATO, 2009).

A norma foi evidentemente traduzida e passou a ser utilizada em uma série de países, incluindo países do eixo ibero-americano.

O conceito de indexação pode ser evidenciado como "a indexação é a parte mais importante da análise documentária. Consequentemente é ela que condiciona o valor de um sistema documentário" (CHAUMIER, 1988, p. 63).

Alguns termos também aparecem na literatura relacionados à indexação, como a catalogação de assuntos dentre outros, porém, uma vez que não são objeto deste trabalho ficaremos com a definição de que, a indexação é um processo 
complexo que visa extrair termos de um determinado documento e de um determinado contexto.

Ora, a descrição e a classificação arquivísticas, descritas no tópico anterior são ao seu modo e respeitando a proveniência e o contexto de produção documental, funções que visam sintetizar e extrair informações dos documentos produzidos no contexto organizacional.

Neste sentido, é possível então compreender a indexação com uma fase do processo de representação arquivística.

Identificando e selecionando-se conceitos e seus conteúdos visando corresponder a uma necessidade de um determinado grupo de usuários.

O processo de representação arquivística funcionaria deste modo:

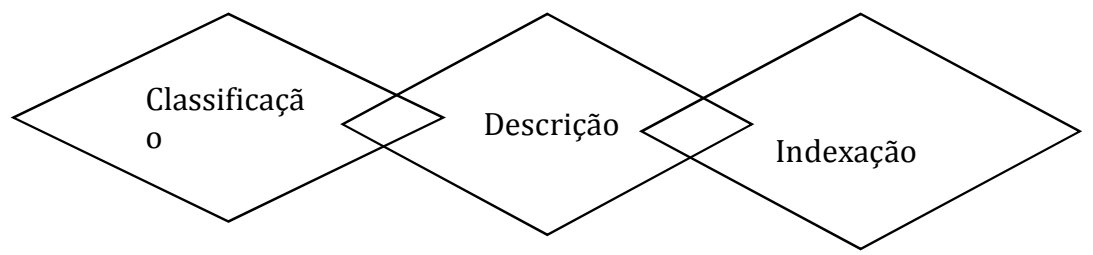

Figura 1: Processo de Representação nos arquivos Fonte: Dados da pesquisa (2016).

A classificação sendo uma atividade limite e baseada no conceito de proveniência e no contexto de produção documental serviria como fundamento para todo o processo de representação.

Após a conclusão e elaboração do plano de classificação entraríamos na fase de descrição, respeitando o fundo e a estrutura classificatória do mesmo, seria decomposto do nível mais alto para o nível mais baixo da estrutura do órgão produtor.

Concluído o processo de descrição entraríamos no processo de indexação, que seria baseado no plano de classificação e da descrição multinível promulgada pelas normas de descrição, se retiraria termos representativos, relacionados ao contexto de produção documental e possivelmente para além dele.

Neste processo os movimentos de análise e síntese, descritos no âmbito da indexação e da análise documentaria ocorreriam de forma simultânea, do nível mais geral para o nível mais específico.

A indexação no âmbito dos arquivos poderia ocorrer por meio da elaboração de índices e posteriormente de vocabulários controlados. Tais ferramentas visam auxiliar o arquivista no acesso aos documentos.

As normas de descrição arquivística citadas anteriormente, estabelecem de forma geral que a indexação pode sim ocorrer no âmbito dos arquivos, porém não estabelece uma regra geral nem um processo.

Visamos com este artigo, sem esgotar o tema, evidentemente, mas iniciar a discussão, fundamental e necessária na atual conjuntura da Arquivística e também aproximá-la das práticas e teorias advindas da organização do conhecimento, da indexação e da Ciência da Informação.

É perceptível ao longo da trajetória descrita que o processo de representação em arquivos é interdisciplinar na medida em que a Arquivística apoia-se em seus princípios e em teorias de outras áreas para a preservação e acesso dos documentos Arquivísticos. 


\section{CONSIDERAÇÕES FINAIS}

A Arquivística possui um desenvolvimento teórico recente no que se refere a suas bases conceituais e seu desenvolvimento metodológico. Buscou-se apresentar aspectos integradores da teoria Arquivística, passíveis de relações com a organização do conhecimento visando uma apropriação por parte de ambas as áreas, uma vez que, os arquivos tornam-se um espaço de aplicação de metodologias da organização do conhecimento e a Arquivística ganha um novo espaço para discussão de seus preceitos histórico-conceituais.

Apresentou-se o histórico de desenvolvimento da descrição e da classificação e estabeleceu-se uma relação entre elas, sinalizando um possível processo de representação.

A partir deste processo de representação aproximou-se teoricamente da indexação buscando apropria-la na realidade de organização de arquivos teoricamente, uma vez que, até o presente momento essa aproximação só ocorre em algumas situações e de forma profundamente pulverizada.

As áreas envolvidas só têm a ganhar com relações desta natureza e estudos como este, devem correr com mais frequência e profundidade visando um aumento dos aparatos metodológicos neste universo.

Evidentemente, são necessários mais estudos voltados ao tema, uma vez que o tema não foi esgotado e sim apresentado como uma possiblidade para o campo. Este trabalho é parte da pesquisa que tem se desenvolvido no âmbito do grupo de pesquisa Representação em Arquivos e Bibliotecas da Universidade ... e sinaliza a aplicabilidade da indexação e da representação no âmbito dos arquivos e da Arquivística e visa estabelecer-se como um dos textos iniciais nesta temática.

\section{REFERÊNCIAS}

BARROS, T. H. B. A representação da informação Arquivística: uma Análise do discurso teórico e institucional a partir dos contextos Espanhol, Canadense e Brasileiro. 222 f. (Tese de Doutorado em Ciência da Informação) - Faculdade de Filosofia e Ciências, Universidade Estadual Paulista, Marília, SP, Brasil, 2014

BARROS, T. H. B.; MORAES, J. B. E. Arquivística, História e Ciência da Informação: diálogos e duelos. In: CETAC.MEDIA e Universidad de León. (Org.). Globalização, Ciência e Informação. 1ed.Porto: Editora da Universidade do Porto, 1 ,2013 p. 168180.

BARROS, T. H. B., TOGNOLI, N.T. Os processos de representação do conhecimento arquivístico: elementos históricos e conceituais da classificação e descrição In:GUIMARÃES, José Augusto Chaves; DODEBEI, Vera. Organização do

Conhecimento e Diversidade Cultural. Marília: Fundepe, 2015, v. 3, p. 94-99.

CHAUMIER, J. Indexação: conceito, etapas, instrumentos. Revista Brasileira de Biblioteconomia e Documentação, São Paulo, v. 21, n. 1/2, p. 63-79, 1988.

CRUZ MUNDET, J. M. Archivística: gestión de documentos y administración de archivos. Madrid: Alianza Editorial S.A., 2012.

CRUZ MUNDET, J. M. Manual de archivística. Madrid: Fundación Germán Sánchez Ruipérez, 2001. 
CRUZ MUNDET, J. M. Princípios, términos y conceptos fundamentales. In: MUNDET, J. R. C. Administración de documentos y Archivos: Textos Fundamentales. Madrid: Guillomía Comunicación Gráfica C. B. Cap. 1, 2011, p. 15-35.

DAY, R. The modern invenction of information: discourse, history and power Carbondale: Southern Illinois University, 2001.

DUCHEIN, M. Theoretical principles and practical problems of respect des fonds in Archival Science. Archivaria, n. 16, p. 64-82, 1983.

DURANTI, L. Origin and development of the concept of Archival Description. Archivaria, n. 35, p. 47-54, 1993.

EASTWOOD. T. Putting the parts of the whole together: systematic arrangement of archives. Archivaria, n. 50, p. 93-116, 2000.

FUJITA, M. S. L. A identificação de conceitos no processo de análise de assunto para indexação. Revista Digital de Biblioteconomia e Ciência da Informação, v. 1, n. 1, p. 60-90, 2003.

FUJITA, M. S. L.; RUBI, M. Elementos de política de indexação em manuais de indexação de sistemas de informação especializados. Perspectivas em Ciência da Informação, v. 8, n. 1, p. 66-77, 2003.

FUJITA, M. S. L. et al. A indexação de livros: a percepção de catalogadores e usuários de bibliotecas universitárias. Um estudo de observação do contexto sociocognitivo com protocolos verbais. UNESP, 2009.

GUIMARÃES, J. A. C. A análise documentária no âmbito do tratamento da informação: elementos históricos e conceituais. In: RODRIGUES, G. M.; LOPES, I. L. (Orgs.). Organização e representação do conhecimento na perspectiva da Ciência da Informação. Brasília: Thesaurus, 2003 p. 100-117.

HEREDIA HERRERA, A. Manual de instrumentos de descripción documental. Sevilla: Diputación Provincial, 1982.

HEREDIA HERRERA, A. Archivística general: teoría y práctica. 7. ed. Sevilla: Servicio de Publicaciones de la Diputación de Sevilla, 1995.

HEREDIA HERRERA, A. Archivos y archiveros entre la Guerra Civil y la España de las Autonomias. In: GENERELO, J. J.; LÓPEZ, A. M. Historia de los Archivos e de la Archivistica en España. Valladolid: Ed. Universidad de Vallavolid. Cap. 7, 1998 p. 175-189.

HJøRLAND, B. What is Knowledge Organization (KO)?. Knowledge Organization. v.35 n. 2, p. 86-102, 2008.

JENKINSON, H. A manual of archive administration: including the problems of war archives and archive making. Oxford: The Clarendon Press, 1922.

RODRIGUES, G. M. A representação da informação em arquivística: uma abordagem a partir da perspectiva da norma internacional de descrição arquivística. In: RODRIGUES, G. M.; LOPES, I. L. (Orgs.). Organização e representação do 
conhecimento na perspectiva da Ciência da Informação. Brasília: Thesaurus, 2, 2003. p. 210-230.

SABOURIN, P. Constructing a funcional-bases recrods classification system: business activity sctructure classification system. Archivaria, n. 51, p. 137-154, 2001.

SHEPHERD, E.; YEO, G. Managing records: a handbook of principles and practice. London: Facet, 2003.

YAKEL, E. Archival Representation. Archival Science, n. 3, p. 31-25, 2003.

Editores do artigo: Adilson Luiz Pinto e Rafaela Paula Schmitz 